\title{
Neoateroesclerosis precoz en un paciente con trasplante cardiaco
}

\section{Accelerated neoatherosclerosis in a heart transplant recipient}

\author{
Rafael Romaguera*, Josep Gómez-Lara y Joan A. Gómez-Hospital \\ Área de Enfermedades del Corazón, Hospital de Bellvitge - IDIBELL, Universidad de Barcelona, L'Hospitalet de Llobregat, Barcelona, España
}

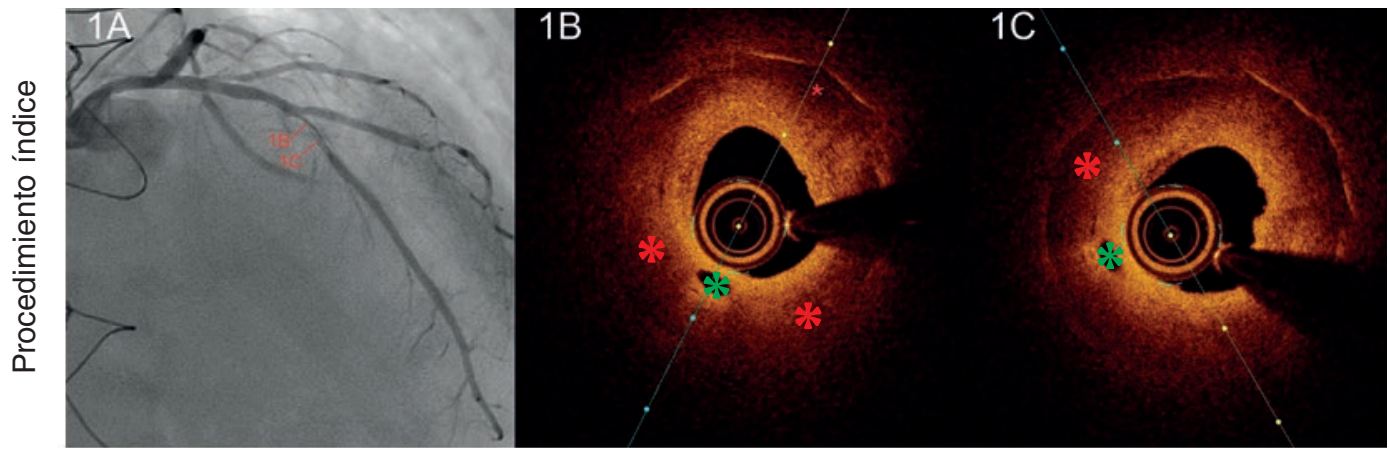

Figura 1.

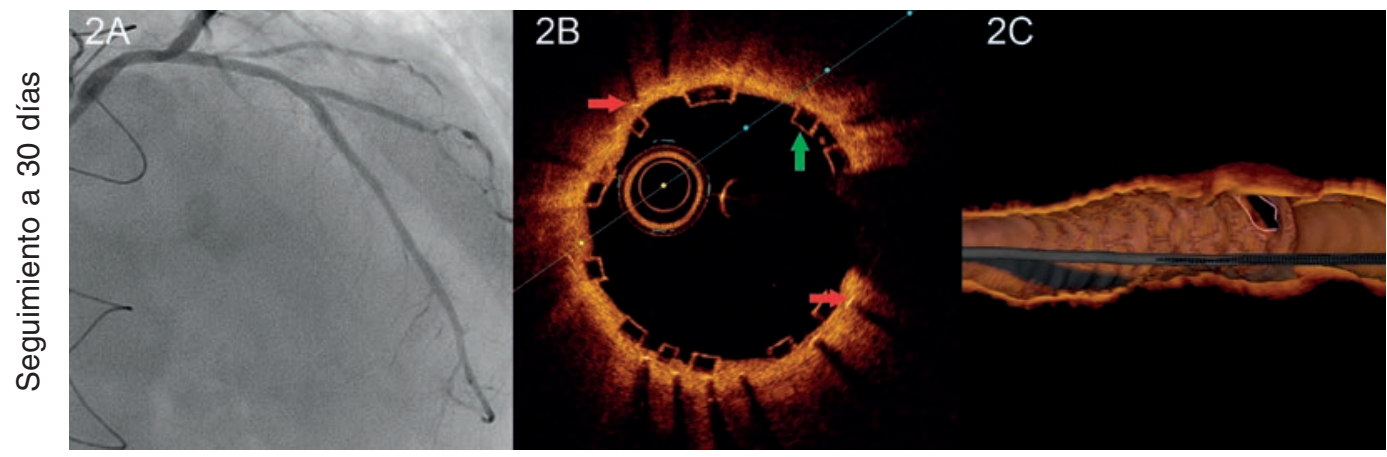

Figura 2.

La vasculopatía del injerto cardiaco se caracteriza por la ausencia de placas ricas en lípidos. No obstante, los receptores de trasplantes también pueden desarrollar lesiones que recuerdan a la ateroesclerosis tradicional. El tacrolimus y el everolimus, que se utilizan habitualmente en los receptores de trasplantes, se asocian a efectos adversos proaterogénicos tales como hiperglucemia, hiperlipemia e hipertensión. El everolimus también libera varias citocinas proinflamatorias tales como la interleucina 6 y el factor de necrosis tumoral- $\alpha$. De ahí que la inflamación, la disfunción endotelial y la hiperlipemia sean procesos fisiopatológicos compartidos comunes a la neoateroesclerosis del stent y a la ateroesclerosis del trasplante.

Presentamos el caso de un varón de 50 años con antecedentes de trasplante cardiaco hace 18 años y un stent liberador de zotarolimus implantado en la arteria descendente anterior izquierda hace 16 meses. El paciente recibió agentes inmunosupresores incluido tratamiento cuádruple con corticosteroides, micofelonato, tacrolimus y everolimus. Fue hospitalizado con un cuadro de insuficiencia cardiaca aguda. La angiografía coronaria que se realizó reveló la presencia de una importante reestenosis del stent (figura 1A). La tomografía de coherencia óptica (OCT) reveló la presencia neoateroesclerosis precoz del stent con una placa cargada de lípidos similar a la apariencia morfológica típica de la neoateroesclerosis nativa (asterisco rojol y vasa vasorum (asterisco verde) (figura 1B, figura 1C). Para evitar muchas capas metálicas (flechas rojas), se implantó en el stent un armazón vascular bioabsorbible (flechas verdes). El seguimiento OCT y angiográfico que se llevó a cabo un mes después confirmó la presencia de permeabilidad del armazón con la mayoría de struts no cubiertos (figura 2A, figura 2B, figura 2C). Se trata de la primera descripción de neoateroesclerosis de stent en un receptor de trasplante que sobrevino pocos meses después de colocar el stent. Como la vasculopatía del injerto cardiaco suele ser silente y catastrófica, se recomienda realizar control metabólico intensivo y monitorización invasiva por imagen en estos pacientes.

* Autor para correspondencia: Hospital Universitari de Bellvitge, Feixa Llarga s/n, 08907 L'Hospitalet de Llobregat, Barcelona, España.

Correo electrónico: rafaromaguera@gmail.com (R. Romaguera).

Online: 29-04-2019

Full English text available from: www.recintervcardiol.org/en.

https://doi.org/10.24875/RECIC.M19000016

2604-7306 / @ 2019 Sociedad Española de Cardiología. Publicado por Permanyer Publications. Este es un artículo open access bajo la licencia CC BY-NC-ND 4.0. 